\title{
Effect of Dent Depth in Ultrasonic Spot Welding Joints used Extruded $\mathrm{Mg}_{96} \mathrm{Zn}_{2} \mathrm{Y}_{2}$ Alloys
}

\author{
Yuichi Higashi $^{1 *}$, Kazuto Futawatari ${ }^{2}$ and Chihiro Iwamoto ${ }^{3}$ \\ 1 Department of Mechanical Engineering, National Institute of Technology, Kagoshima College, Kirishima 899-5193, Japan \\ 2 Graduate School of Frontier Sciences, The University of Tokyo, Kashiwa 277-8563, Japan \\ 3 Graduate School of Science and Technology, Ibaraki University, Hitachi 316-8511, Japan \\ * Corresponding author: Fax: 81-995-42-9103, and/or e-mail: higashi@kagoshima-ct.ac.jp
}

\begin{abstract}
An extruded $\mathrm{Mg}_{96} \mathrm{Zn}_{2} \mathrm{Y}_{2}$ alloy has excellent mechanical properties and a flame-retardant. The alloys have two phases of an Mg matrix and a long-period stacking ordered structure phase (LPSO phase) extended along the extrusion direction. By contrast, the ultrasonic welding technology is a solid-state bonding and the welding is achieved by the severe plastic deformation in the welding processes. However, the dents generated during the welding process are often taken up as issues that affect the weldability. This paper evaluated the relationship between the dent depth and the microstructure in the joints when the welding conditions are kept constant.

After welding, the plastic flow due to the folding phenomenon was observed. When the dent depths became excessive and the sheet thickness reduction rate increased, the LPSO phases extending in the extrusion direction was not maintained. And, the morphology changed into mottled and platelike LPSO phases. The continuity of the originally LPSO phases was lost, and the plastic deformation progressed during the welding process. It was considered that the heat generated during the process and the severe plastic deformation were the cause. And then, in the joints with the largest sheet thickness reduction rate, a molten structure was formed.

Key words: Ultrasonic spot welding, Magnesium alloys, LPSO phases, Plastic deformation, microstructure
\end{abstract}

\section{INTRODUCTION}

$\mathrm{Mg}$ and the alloys are the lightest in utility metals. They have an excellent specific strength, and applications as lightweight structural members in the automotive and aircraft industries have been expected [1], [2], [3] and [4]. In recent years, a flame-retardant $\mathrm{Mg}$ alloy in which tensile strength exceeded $400 \mathrm{MPa}$ has been developed, and one of the alloys is an extruded $\mathrm{Mg}_{96} \mathrm{Zn}_{2} \mathrm{Y}_{2}$ alloy which $\mathrm{Zn}$ and $\mathrm{Y}$ were added [5], [6] and [7]. The alloys have two phases of an $\mathrm{Mg}$ matrix and a long-period stacking ordered structure phase (LPSO phase), and the LPSO phases exhibit morphology extended along the extrusion direction [6], [7], [8], [9], [10] and [11], as shown in Fig. 1, where, the Mg matrix and the LPSO phases are imaged dark contrast and bright contrast, respectively. Material studies on the alloys have been actively conducted [5], [6], [7], [8], [9], [10], [11], [12],

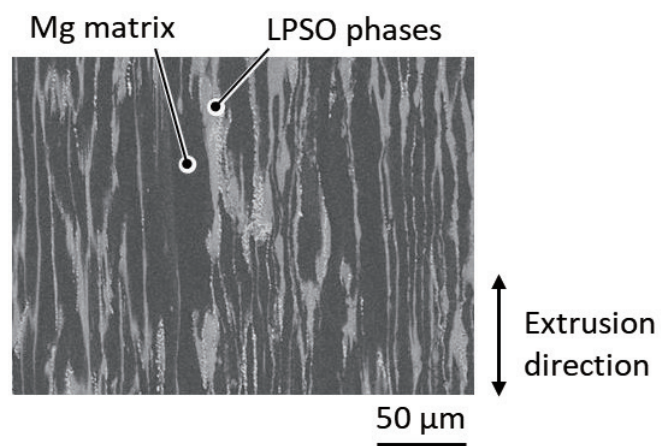

Fig. 1 Microstructure of the extruded $\mathrm{Mg}_{96} \mathrm{Zn}_{2} \mathrm{Y}_{2}$ alloys
[13], [14], [15] and it has been revealed that both the $\mathrm{Mg}$ matrix and the LPSO phases contribute to the excellent mechanical properties [5], [9] and [11]. In the LPSO type $\mathrm{Mg}$ alloys, the LPSO phases also affect the plastic deformation behavior such as anisotropy. However, there are few studies for practical use of the alloys, and the development of welding technology is necessary for the novel materials.

Our study group has been developing an ultrasonic spot welding technology for the LPSO type Mg alloys [16], [17], [18] and [19]. The ultrasonic welding technology is a solid-state bonding that the welding is achieved by the removal of the surface oxide layers caused by the friction by the ultrasonic vibration and the severe plastic deformation in the welding processes [20] and [21]. The energy required for welding is significantly lower than that of conventional resistance spot welding, and the welding is a clean welding technology in the processes of the manufacturing technique [22], [23], [24], [25] and [26]. The ultrasonic welding has been widely using for welding, such as harnesses and terminals that do not require high welding strength. In addition, it has been actively studied to apply the ultrasonic welding as a welding technology for structural members [16], [17], [18], [19], [20], [21], [22], [23], [24], [25], [26], [27], [28], [29], [30], [31], [32], [33], [34], [35]. However, there are some issues, and one of the issues is to form a dent at a joint during the ultrasonic spot welding process. That is, the dent affects the weld strength and the fracture modes [20]. In addition, the appearance quality is also impaired. The main goal of this study is to control the dent depth 
at the joints and create the joints with excellent weldability. This paper evaluated the effects of the progress of the dent depth on the microstructure evolution in the joints when the welding conditions were kept constant. And then, phenomena occurred during the process were discussed.

\section{EXPERIMENTAL PROCEDURE}

As materials, the extruded $\mathrm{Mg}_{96} \mathrm{Zn}_{2} \mathrm{Y}_{2}$ alloys of approximately $\varnothing 22 \mathrm{~mm}$ were used in this study. The materials were cut in sliced plates and specimens with 0.8 $\mathrm{mm}$ in thickness were prepared. The faying surfaces were ground using 2000 waterproof abrasive paper.

Fig. 2 (a) shows a schematic illustration of ultrasonic spot welding. The welding machine consisted of an ultrasonic welder (Toshiba Mitsubishi-Electric Industrial Systems Corporation) and an oscillator (Sonomac Japan INC.,). The ultrasonic vibration from the transducer is transmitted to the specimens which were set on the anvil via the welding tip. At the same time, the clamping force is applied vertically. As welding conditions, the constant power, the vibration frequency, the welding energy, and the clamping force were set $1200 \mathrm{~W}, 20 \mathrm{kHz}, 2300 \mathrm{~J}$ and $1980 \mathrm{~N}$, respectively. The welding condition was constant in this paper. And then, the condition was followed from the previous study [18].

In the ultrasonic spot welding, a joint was welded as a lap joint, as shown in Fig. 2 (b). The center of the joints was cut to observe the microstructure in the joints, and the cut surface was parallel to the direction of the ultrasonic vibration. The cross-section was mechanically polished and finished to a mirror surface. The microstructure observation was carried out using scanning electron microscopy (SEM) (Jeol JSM-6010LA) and the SEM observations were obtained using an acceleration voltage of $15 \mathrm{kV}$.

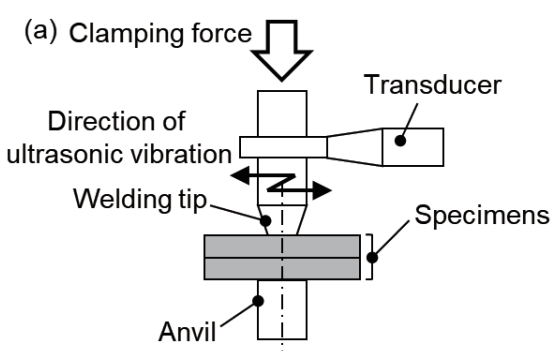

(b) Cut cross-section

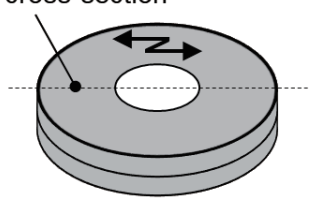

Fig. 2 Schematic illustration: (a) ultrasonic spot welding, (b) welded samples.

\section{RESULTS AND DISCUSSION}

3.1 Welding experiments

Fig. 3 shows appearance images of the welded samples. Fig. 3 (a) shows a sample in which two specimens were completely overlapped. And then, the dent depth of the sample was approximately $0.47 \mathrm{~mm}$, the sheet thickness reduction rate was approximately $29.4 \%$. The movement distance of the welding tip until the welding tip contacted the specimens and the welding was completed is displayed as a displacement on the control monitor. And the displacement was defined as the dent depth of the joints in this experiment. The sheet thickness reduction rates were calculated by dividing the dent depth by the thickness of the two specimens. By contrast, the specimens were displaced, and the overlap margin was changed, as shown in Fig 3 (b) and (c). And the welding position was the center of the overlap margin. By this, the dent depths could be changed under certain welding conditions. The dent depths of the samples of Fig. 3 (b) and (c) were $0.56 \mathrm{~mm}$ and $0.67 \mathrm{~mm}$, respectively. And the sheet thickness reduction rates were approximately $35.0 \%$ and $41.9 \%$, respectively. And the samples in which the dent depths got deeper every approximately $0.1 \mathrm{~mm}$ were selected.

(a)

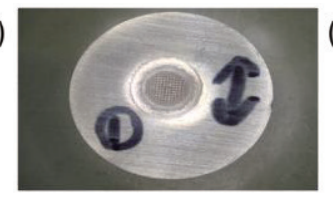

(b)

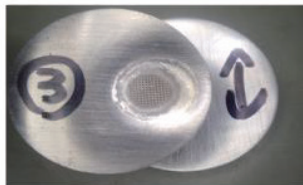

(c)

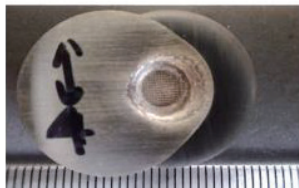

Fig. 3 The welded samples with different sheet thickness reduction rates: (a) $29.4 \%$. (b) $35.0 \%$ (c) $41.9 \%$.

3.2 Microstructure observation in the joints

In order to discuss various phenomena during the welding process depending on the dent depths, the microstructure in the joints was observed. Fig. 4 shows SEM images of the cross-section at each sheet thickness reduction rate. At the sheet thickness reduction rate of $29.4 \%$ in Fig. 4 (a), the morphology of the LPSO phases extending in the extrusion direction was almost maintained, but it was observed that the material was extruded toward the outside of the joints. This phenomenon was suggested by Fukuda et al. [36] and draws the folding phenomenon that occurs during the ultrasonic spot welding process. The folding phenomenon contributes to the enhancement of plastic deformation and the enlargement of the weld region during the welding process. And then, the phenomenon was discussed in detail in previous studies [17] and [18]. The plastic flow was observed in all joints, as shown in Fig. 4 (b) and (c). However, when the sheet thickness reduction rates were excessive, the plastic deformation in the top plates was more severe. And the morphology of the LPSO phases extending in the extrusion direction was not maintained. It was considered to be due to the clamping force and the ultrasonic vibration which applied directly to the top plate via the welding tip.

Fig. 5 shows SEM images around the welded interface enlarged the center of the joints, and the black arrows in the figure indicate the welded interface. As described above, the morphology of the LPSO phase changed drastically when the sheet thickness reduction rate of the 
(a)

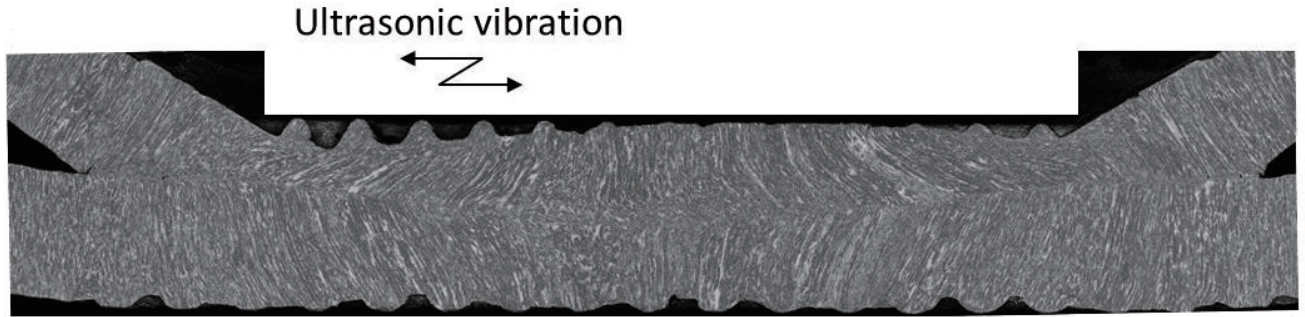

$500 \mu \mathrm{m}$

(b)

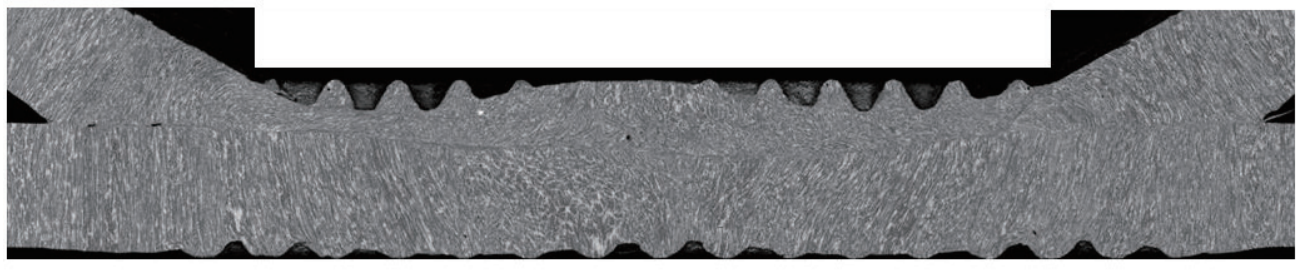

$500 \mu \mathrm{m}$

(c)

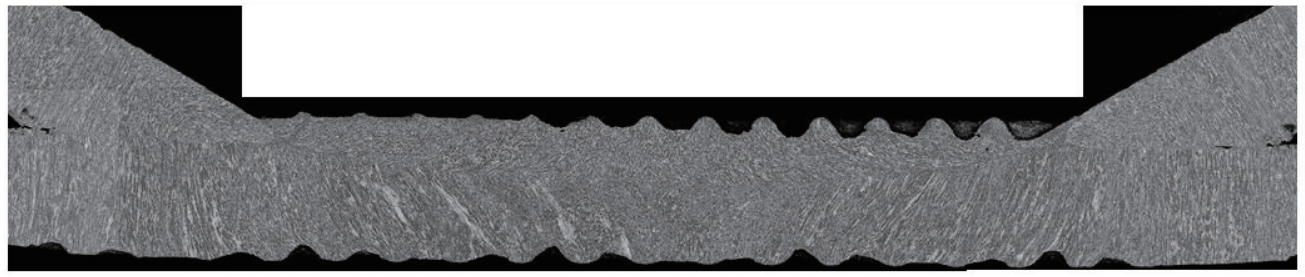

$500 \mu \mathrm{m}$

Fig. 4 SEM images of the cross section at each sheet thickness reduction rates. (a) $29.4 \%$. (b) $35.0 \%$ (c) $41.9 \%$.

(a)

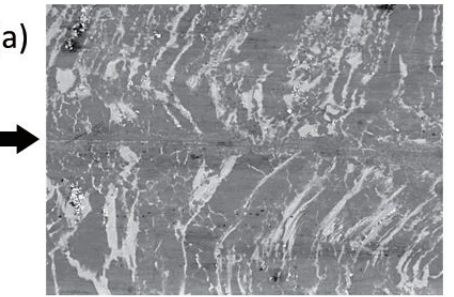

$50 \mu \mathrm{m}$ (b)

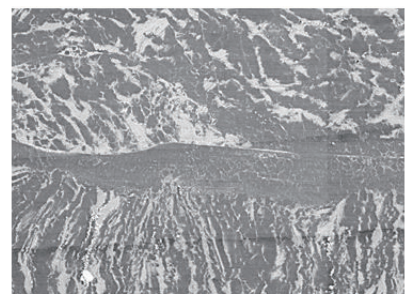

$-50 \mu \mathrm{m}$ (c)

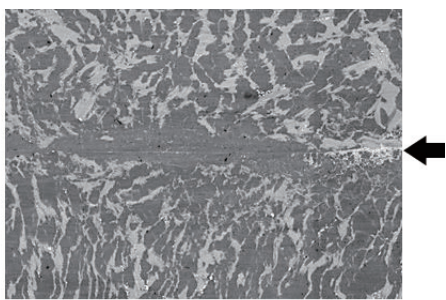

$50 \mu \mathrm{m}$

Fig. 5 SEM images around the welded interface enlarged the center of the joints. (a) $29.4 \%$. (b) $35.0 \%$ (c) $41.9 \%$.

joints became excessive, and it changed into the mottled morphology. The slip systems of the LPSO phase are lower than that of the $\mathrm{Mg}$ matrix and the plastic deformation is difficult to occur [9] and [11]. In this process, the LPSO phases extending in the extrusion direction crosses the shear deformation caused by ultrasonic vibration. As a result, by changing into the mottled morphology from the morphology of the originally LPSO phases, the welding process progressed under the severe plastic deformation. That is, it was considered that the shear deformation limited by the originally LPSO phases was shifted to the shear deformation by the $\mathrm{Mg}$ matrix due to the discontinuous LPSO phases which changed from the originally LPSO phases. And then, the deformation during the welding process progressed under certain conditions, and it affected macroscopic plastic deformation.

In the joint with the sheet thickness reduction rate of $41.9 \%$, Fig. 6 shows an SEM image that further enlarged the vicinity of the welded interface. In the mottled LPSO

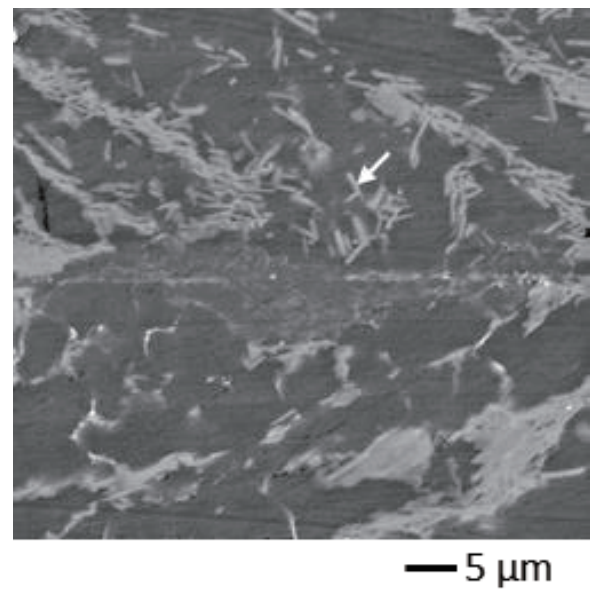

Fig. 6 SEM image of plate-like LPSO phases which were observed along the welded interface in the joints with sheet thickness reduction rate of $41.9 \%$ 
phases, plate-like LPSO phases of approximately $3 \mu \mathrm{m}$ were observed as indicated by the arrow in the figure. The plate-like LPSO phases were observed in a wide region along the welded interface. This is similar to the LPSO phases observed after heat treatment at approximately $500{ }^{\circ} \mathrm{C}$ for 1 hour in the study by Noda et al. [5] and Hagihara et al. [9]. In contrast, the temperature rises to approximately $500{ }^{\circ} \mathrm{C}$ in the ultrasonic welding process, but the holding time is extremely short [19]. That is, it was suggested that the effect on the microstructure by the temperature rise was remarkable under the dynamic condition that severe shear deformation was applied. In the ultrasonic welding process, the main factors which affect the welding mechanism are considered to be the shear deformation and the heat generation. The plastic deformation was enhanced by the change into the mottled morphology from the originally LPSO phases extending along the extrusion direction. And then, the temperature rise in the short time caused by the frictional heat generated by ultrasonic vibration and the heat generated by plastic deformation in addition to the severe plastic deformation contributed to occurrence the plate-like LPSO phases.

Furthermore, in the joint with the sheet thickness reduction rate of $41.9 \%$, a net-like structure was locally observed near the welded interface, as shown in Fig. 7. The net-like structure was occurred in places along the welded interface. In the study of Iwamoto et al. [37], the weldability of $\mathrm{Mg}_{96} \mathrm{Zn}_{2} \mathrm{Y}_{2}$ alloys applied the resistance spot welding was analyzed. The net-like structure closely resembled the molten structure in the nugget of the $\mathrm{Mg}_{96} \mathrm{Zn}_{2} \mathrm{Y}_{2}$ alloys welded by the resistance spot welding. As mentioned above, the temperature during the ultrasonic welding process could be estimated to have risen to approximately $500{ }^{\circ} \mathrm{C}$, but it did not reach the melting temperature of this alloy. In this experiment, only the dent depths of the joints increased under certain welding conditions. And then, the distance between the welding tip and the anvil of the welding machine became significantly narrow in the joint with the sheet thickness reduction rate of $41.9 \%$. That is, the concentration of heat in the joints that was generated during the welding process increased. Therefore, the temperature in the joints rose, and the molten structure was formed in the ultrasonic spot welding process.

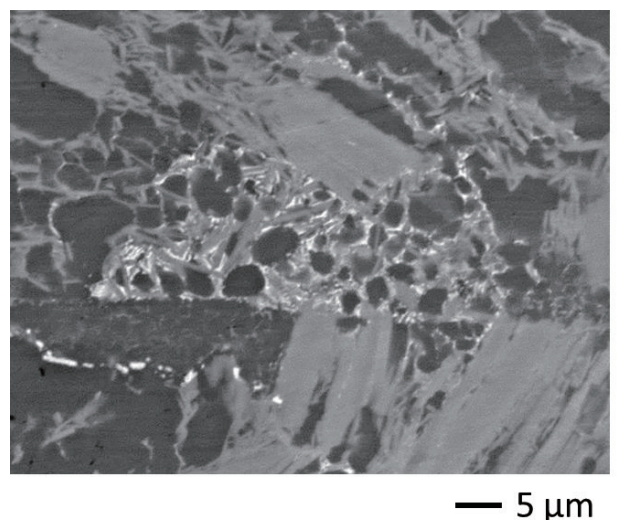

Fig. 7 SEM image of net-like structure which was occurred in places along the welded interface in the joints with sheet thickness reduction rate of $41.9 \%$

\section{CONCULUSIONS}

In this study, the extruded $\mathrm{Mg}_{96} \mathrm{Zn}_{2} \mathrm{Y}_{2}$ alloys were welded by applying the ultrasonic spot welding technology. The welding was conducted under certain welding conditions, and the effect of the dent depths in the joints was evaluated. Novel knowledge was summarized below.

The morphology of the LPSO phases extending in the extrusion direction was not maintained when the sheet thickness reduction rate of the joints became excessive, and it changed into the mottled morphology. In the mottled LPSO phases, the plate-like LPSO phases were observed. In addition, the net-like molten structure was also observed locally.

The heat generation during the ultrasonic welding process is an important factor to achieve the welding. However, the heat generation is dependent on the dent depths of the joints and affects the microstructure. Therefore, it is preferable to control the dent depths that occurred during the welding process.

\section{ACKNOWLEDGMENTS}

This work was supported by JSPS KAKENHI Grant Number JP 17K06829 (Grant-in-Aid for Scientific Research $(\mathrm{C}))$.

\section{REFERENCES}

[1] L. M. Zhao and Z. D. Zhang, Scr. Mater., 58, 283-286 (2008).

[2] A. A. Luo, Mater. Sci. Forum., 419-422, 57-66 (2003)

[3] X. Cao and M. Jahazi, Mater. Des., 30, 2033-2042 (2009).

[4] L. Liu, X. Qi and Z. Wu, Mater. Lett., 64, 89-92 (2010).

[5] M. Noda, T. Mayama and Y. Kawamura, Mater. Trans., 50, 2526-2531 (2009).

[6] S. Yoshimoto, M. Yamasaki and Y. Kawamura, Mater. Trans., 47, 959-965 (2006).

[7] Y. Kawamura and M. Yamasaki, Mater. Trans., 48, 2986-2992 (2007).

[8] E. Abe, Y. Kawamura, K. Hayashi and A. Inoue, Acta Mater., 50, 3845-3857 (2002).

[9] K. Hagihara, A.Kinoshita, Y. Sugino, M. Yamasaki, Y. Kawamura, H. Y. Yasuda and Y. Umakoshi, Acta Mater., 58, 6282-6293 (2010).

[10] E. Abe, A. Ono, T. Itoi, M. Yamasaki and Y. Kawamura, Philos. Mag. Lett., 91, 690-696 (2011).

[11] K. Hagihara, N. Yokotani and Y. Umakoshi, Intermetallics, 18, 267-276 (2010).

[12] K. Shiraishi, T. Mayama, M. Yamasaki and Y. Kawamura, Mater. Sci. Eng. A., 672, 49-58 (2016).

[13] K. Hagihara, Z. Li, M. Yamasaki, Y. Kawamura and T. Nakano, Acta Mater., 163, 226-239 (2019).

[14] K. Hagihara, Z. Li, M. Yamasaki, Y. Kawamura and T. Nakano, Mater. Lett., 214, 119-122 (2018).

[15] S. Hosokawa, K. Kimura, J. R. Stellhorn, K. Yoshida, K. Hagihara, H. Izuno, M. Yamasaki, Y. Kawamura, Y. Mine, K. Takashima, H. Uchiyama, S. Tsutsui, A. Koura and F. Shimojo, Acta Mater., 146, 273-279 (2018).

[16] Y. Higashi, C. Iwamoto, Y. Kawamura, J Japan Inst. Met. Mater., 79, 176-82 (2014) (in Japanese).

[17] Y. Higashi, C. Iwamoto and Y. Kawamura, Mater. Sci. Eng. A., 651, 925-934 (2016).

[18] Y. Higashi, C. Iwamoto, Y. Kawamura, Trans. Mat. 
Res. Soc. Japan, 45, 263-266 (2018).

[19] Y. Hoshi, C. Iwamoto and Y. Higashi, Quarterly Journal of JWS, 36, 185-192 (2018).

[20] A. Macwan, V. K. Patel, X. Q. Jiang, C. Li, S. D. Bhole and D. L. Chen, Mater. Des., 62, 344-351 (2014).

[21] M. Shakil, N. H. Tariq, M. Ahmad, M. A. Choudhary, J. I. Akhter and S. S. Babu, Mater. Des., 55, 263-273 (2014).

[22] E. Mariani and E. Ghassemieh, Acta Mater., 58, 2492-2503 (2010).

[23] C. Y. Kong, R. C. Soar, P. M. Dickens, J Mater. Process. Tech., 146, 181-187 (2004).

[24] E. T. Hetrick, J. R. Baer, W. Zhu, L. V. Reatherford, A. J. Grima, D. J. Scholl, D. E. Wilkosz, S. Fatima and S. M. Ward, Weld. J., 88, 149-158 (2009).

[25] U. I. Chang and J. Frisch, Weld. J., 53, 24-35 (1974).

[26] D. Bakavos and P. B. Prangnell, Mater. Sci. Eng. A., 527, 6320-6334 (2010).

[27] V.K. Patel, S.D. Bhole and D.L. Chen, Mater. Sci. Eng. A., 569, 78-85 (2013).
[28] Y. C. Chen, D. Bakavos, A. Gholonia and P. B. Prangnell, Acta Mater., 60, 2816-2828 (2012).

[29] H. T. Fujii, M. R. Sriraman and S. S. Babu, Metall. Mater. Trans. A., 42A, 4045-4055 (2011).

[30] M. R. Sriraman, S. S. Babu and M. Short, Scr. Mater., 62, 560-563 (2010).

[31] T. Watanabe, H. Sakuyama and A. Yanagisawa, $J$ Mater. Process. Tech., 209, 5475-5480 (2009).

[32] C. Iwamoto, Metall. Mater. Trans. A., 45, 1371-1375 (2014).

[33] H. T. Fujii, Y. Goto, Y. S. Sato and H. Kokawa, Scr. Mater., 116, 135-138 (2016).

[34] V. K. Patel, S. D. Bhole and D. L. Chen, Scr. Mater., 65, 911-914 (2011).

[35] V. K. Patel, S. D. Bhole and D. L. Chen, Mater. Des., 45, 236-240 (2013).

[36] H. Fukuda, T. Kameda, Y. Takahashi and T. Tomimura, Mate2004., 10, 197-202 (2004) (in Japanese). [37] C. Iwamoto, S. Satonaka and Y. Kawamura, Mater. Sci. Forum., 706-709, 1181-1186 (2012).

(Received April 30, 2020; Accepted June 30, 2020; Published Online August 1, 2020) 